\title{
Aklimatisasi Anggrek (Phalaepnopsis amabilis) dengan Media Tanam yang Berbeda dan Pemberian Pupuk Daun
}

\author{
Acclimatization of Orchid (Phalaepnopsis amabilis) with Different Plant Substrate \\ and Giving of Leaf Fertilizer
}

\author{
Etik Wukir Tini1*, Prasmaji Sulistyanto $^{1}$, dan Gregorius Hadi Sumartono ${ }^{1}$
}

Diterima 22 November 2018/Disetujui 02 April 2019

\begin{abstract}
The purpose of the research is to find the most appropriate planting medium and the concentration of leaf fertilizer for acclimatization of Phalaenopsis orchids in order to increase the plant growth. The research was conducted from November 2017 to June 2018 in the screen house. The design was laid in Randomized Completed Block Design with two treatment factors, the first one is the planting medium (fern, cocofiber, and kadaka root) and the second one is the concentration of

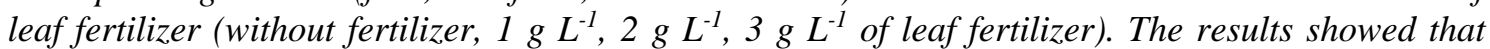
kadaka roots could increase the leaf area growth by $19.2 \%$ compared to ferns and $26.67 \%$ compared to coconut fiber. Leaf fertilizer concentration of $2 \mathrm{~g} \mathrm{~L}^{-1}$ is the best concentration that can increase in leaf area addition by $78.31 \%$ and the amount of chlorophyll by $25.58 \%$. The combination of plant substrate types and fertilizer concentration have not increased the growth of Phalaenopsis orchid plants in the acclimatization phase.
\end{abstract}

Keywords: coconut fiber, concentration, fern, plant growth, kadaka root

\begin{abstract}
ABSTRAK
Penelitian bertujuan mendapatkan media tanam dan konsentrasi pupuk daun yang paling tepat untuk aklimatisasi anggrek Phalaepnopsis agar meningkatkan pertumbuhan tanaman. Penelitian dilaksanakan November 2017 sampai Juni 2018 di rumah kasa. Rancangan percobaan yang digunakan Rancangan Kelompok Lengkap Teracak dengan dua factor perlakuan, faktor pertama adalah media tanam (pakis, sabut kelapa, dan akar kadaka), dan faktor yang kedua adalah konsentrasi pupuk daun ( tanpa diberi pupuk daun, pupuk daun dengan konsentrasi $1 \mathrm{~g} \mathrm{~L}^{-1}, 2 \mathrm{~g} \mathrm{~L}^{-1}, 3 \mathrm{~g} \mathrm{~L}^{-1}$ ). Hasil penelitian menunjukkan bahwa akar kadaka dapat meningkatkan pertambahan luas daun sebesar $19.2 \%$ dibandingkan pakis dan 26.67\% dibandingkan sabut kelapa. Konsentrasi pupuk daun Greener $2 \mathrm{~g} \mathrm{~L}^{-1}$ merupakan konsentrasi paling baik yang dapat meningkatkan pertambahan luas daun sebesar $78.31 \%$ dan pertambahan jumlah klorofil $25.58 \%$. Kombinasi jenis media tanam dan konsentrasi pupuk belum meningkatkan pertumbuhan tanaman anggrek Phalaenopsis pada fase aklimatisasi.
\end{abstract}

Kata kunci: akar kadaka, konsentrasi, pakis, pertumbuhan tanaman, sabut kelapa

${ }^{1}$ Program Studi Agroteknologi, Fakultas Pertanian Universitas Jenderal Soedirman J1. Dr. Suparno 73, Karangwangkal, Purwokerto, 53122

E-mail : etik.unsoed@gmail.com (*Penulis korespondensi) 


\section{PENDAHULUAN}

Phalaenopsis termasuk jenis anggrek epifit, yaitu anggrek yang hidup menempel pada inang tanpa merugikan inangnya. Anggrek epifit memiliki akar yang berambut pendek atau nyaris tidak berambut dan dapat ditanam dengan cara ditempelkan langsung pada akar pakis yang ringan, agak longgar, atau jarang susunan seratnya, sehingga mudah dimasuki akar-akar yang halus (Latif, 1960). Penggunaan media tanam yang tepat dalam budidaya anggrek diharapkan dapat menciptakan lingkungan perakaran yang baik, serta dapat menyimpan air dan unsur hara untuk kebutuhan tanaman anggrek, sehingga dapat mendukung pertumbuhan tanaman anggrek dengan baik. Salah satu faktor penting dalam pengembangan anggrek bulan adalah pemilihan jenis media yang sesuai untuk mendukung pertumbuhannya. Media untuk pemindahan anggrek harus disesuaikan dengan jenis anggrek, iklim dan ketersediaannya. Beberapa bahan yang dapat digunakan sebagai media tanam anggrek adalah pakis, sabut kelapa, arang, dan lumut (Kartana, 2017). Penggunaan media yang memiliki porositas tinggi mendukung pertumbuhan akar namun media beresiko akan lebih cepat mengalami kekurangan air. Sebaliknya, apabila menggunakan media dengan porositas yang rendah dapat menghambat pertumbuhan akar meskipun daya pegang air mungkin lebih baik daripada yang media ringan (Ari et al., 2016).

Pemberian unsur hara pada tanaman anggrek umumnya diberikan lewat daun. Pupuk daun adalah unsur-unsur hara yang diberikan melalui daun dengan cara penyemprotan atau penyiraman kepada daun tanaman agar langsung dapat diserap guna mencukupi kebutuhan bagi pertumbuhan dan perkembangan (Sutedjo, 1999). Seperti tumbuhan lainnya, anggrek selalu membutuhkan unsur hara untuk mempertahankan hidupnya. Anggrek membutuhkan waktu yang cukup lama untuk memperlihatkan gejala-gejala defisiensi, hal tersebut dikarenakan pertumbuhan anggrek yang sangat lambat. Pupuk yang umum digunakan pada tanaman anggrek untuk memenuhi kebutuhan unsur guna memacu pertumbuhan yang baik adalah pupuk majemuk yaitu pupuk yang mengandung unsur makro dan mikro.
Pupuk daun yang dibutuhkan untuk masa pertumbuhan vegetatif awal adalah pupuk daun majemuk N-P-K dengan komposisi nitrogen $(\mathrm{N})$ lebih tinggi dari unsur lain. Beberapa pupuk yang biasa digunakan untuk aklimatisasi anggrek sebagai berikut (dengan kandungan N-P-K): pupuk Gandasil D (30-1010), Hyponex (20-20-20), Growmore hijau (2020-20), dan Farmer (20-8-8). Konsentrasi pupuk yang dilarutkan dalam air yang akan digunakan untuk pemupukan menjadi hal penting untuk diketahui karena berkaitan dengan efisiensi pemupukan, jumlah pupuk yang dilarutkan harus tepat sehingga pemakaian pupuk dapat sesuai yaitu tidak berlebihan namun menghasilkan dampak pertumbuhan yang baik pada tanaman.

Tujuan penelitian yaitu mendapatkan jenis media, konsentrasi pupuk daun, serta interaksi media tanam dan konsentrasi pupuk daun paling tepat digunakan untuk aklimatisasi anggrek bulan agar dapat meningkatkan dan mempercepat pertumbuhan tanaman

\section{BAHAN DAN METODE}

Penelitian dilaksanakan di rumah kasa Desa Banjarsari kulon, Kecamatan Sumbang, Banyumas dan Laboratorium Tanah/ Sumberdaya Lahan, Fakultas Pertanian Universitas Jenderal Soedirman. Penelitian dilaksanakan dari bulan November 2017 sampai Juni 2018. Bahan penelitian yang digunakan meliputi bibit anggrek Phalaenopsis berumur 40 hari setelah aklimatisasi, pupuk daun Greener (dengan kandungan NPK:17.3-55), air, pakis, serat sabut kelapa, akar kadaka, fungisida Dithane M-45 dengan bahan aktif Mankozeb, cat kuku dan atonik $6.5 \mathrm{~L}$. Alat yang digunakan dalam penelitian ini adalah alat tulis, chlorophyll meter SPAD-502 plus (Konica Minolta), mikroskop, jangka sorong Sellery 54808, thermohigrometer HTC-2, mistar, handsprayer yoto $2 \mathrm{~L}$, gelas ukur pyrex $10 \mathrm{ml}$, digital lux meter MS6612, pH meter, Pot, dan kertas milimeter blok kerang mas.

Rancangan percobaan yang digunakan yaitu rancangan kelompok lengkap teracak dengan 2 faktor perlakuan: jenis media tanam dan konsentrasi pupuk daun Greener. Perlakuan media tanam terdiri atas tiga jenis media tanam dan konsentrasi pupuk daun Greener dengan empat taraf, sehingga menghasilkan 12 
perlakuan dan diulang 3 kali sehingga total terdapat 48 unit percobaan. Perlakuan jenis media tanam terdiri atas pakis, sabut kelapa, dan akar kadaka. Konsentrasi pupuk daun terdiri atas kontrol (tanpa dipupuk), $1 \mathrm{~g} \mathrm{~L}^{-1}, 2 \mathrm{~g}$ $\mathrm{L}^{-1}$, dan $3 \mathrm{~g} \mathrm{~L}^{1}$.

Aklimatisasi adalah kegiatan memindahkan bibit anggrek Phalaenopsis dari dalam botol ke dalam pot besar yang dilakukan dengan cara bibit dikeluarkan dari botol, kemudian dibersihkan dari sisa media yang masih menempel menggunakan larutan atonik. Selanjutnya, bibit anggrek ditanam dalam kompot satu per satu. Satu pot besar berisi 3040 bibit. Pemeliharaan bibit anggrek dalam kompot dengan penyiraman air yang dilakukan dengan frekuensi 1 kali per hari pada sore hari, penyiraman dengan cara pengkabutan air pada tanaman, pemberian larutan atonik setiap 2 kali per minggu dengan konsetrasi $1 \mathrm{ml} \mathrm{L}^{-1}$, dan disertakan aplikasi fungisida setiap 1 kali per minggu. Bibit anggrek Phalaenopsis dipelihara di dalam kompot selama 40 hari, selanjutnya, bibit dipindah ke pot kecil per individu. Pemeliharaan dengan penyiraman air yang dilakukan dua kali sehari pada pagi dan sore hari. Pemupukan dilakukan sekali dalam seminggu pada sore hari dengan konsentrasi sesuai perlakuan yaitu $0 \mathrm{~g} \mathrm{~L}^{-1}, 1 \mathrm{~g} \mathrm{~L}^{-1}, 2 \mathrm{~g} \mathrm{~L}^{-1}$, dan $3 \mathrm{~g} \mathrm{~L}^{-1}$. Penyemprotan atonik dan fungisida dilakukan sekali seminggu dengan dosis masing-masing yaitu $1 \mathrm{mg} \mathrm{L}^{-1}$ dan $3 \mathrm{~g} \mathrm{~L}^{-1}$. Atonik berfungsi sebagai ZPT dan fungisida untuk mencegah tumbuhnya cendawan.

Nilai $\mathrm{pH}$ pupuk daun yang telah dilarutkan dalam air dengan konsentrasi yang berbeda memiliki nilai yang berbeda yaitu 6.68 untuk larutan $1 \mathrm{~g} \mathrm{~L}^{-1}, 6.54$ untuk larutan $2 \mathrm{~g} \mathrm{~L}^{-}$ ${ }^{1}$, dan 6.49 untuk larutan $3 \mathrm{~g} \mathrm{~L}^{-1}$, pengukuran $\mathrm{pH}$ pupuk daun dilakukan di Laboratorium Tanah/Sumberdaya Lahan Fakultas Pertanian

\section{HASIL DAN PEMBAHASAN}

\section{Kondisi Umum}

Kondisi umum dalam rumah kasa $28{ }^{\circ} \mathrm{C}$ pada pagi hari, $32{ }^{\circ} \mathrm{C}$ pada siang hari, dan $27^{\circ} \mathrm{C}$ pada sore hari, dengan kelembaban rerata $89 \%$ pada pagi hari, $72 \%$ pada siang hari, dan $80 \%$ pada sore hari, serta intensitas cahaya rerata yaitu 769 Lux pada pagi hari, 982 Lux pada siang hari, dan 439 Lux pada sore hari.
Bibit anggrek Phalaenopsis berada pada pot besar pada hari ke-1 sampai ke-40, kemudian dipindahkan pada pot individu pada hari ke-40. Pengamatan dan pemupukan dilakukan setelah bibit anggrek berada pada pot individu dari minggu ke-1 sampai ke-16 dengan frekuensi pengamatan yang berbeda pada beberapa variabel sesuai dengan waktu pengamatan yang telah ditentukan, dan pemupukan dilakukan sebanyak 1 kali per minggu.

\section{Hasil}

Hasil analisis ragam Tabel 1 menunjukkan bahwa jenis media tanam berpengaruh sangat nyata terhadap satu variabel pengamatan yaitu pertambahan luas daun, namun tidak berpengaruh nyata pada pertambahan jumlah daun, diameter batang, pertambahan jumlah klorofil, dan jumlah stomata. Perlakuan konsentrasi pupuk daun memberikan hasil yang sangat nyata terhadap pertambahan luas daun dan pertambahan jumlah klorofil, namun tidak berpengaruh nyata terhadap pertambahan jumlah daun, pertambahan diameter batang, dan jumlah stomata. Menunjukkan tidak adanya interaksi antara faktor jenis media tanam dan konsentrasi pupuk daun pada semua variabel yang diamati.

\section{Pengaruh Perlakuan Jenis Media Tanam terhadap Variabel Pengamatan}

Tabel 2 menunjukkan nilai rerata hasil pengamatan setiap variabel. Jenis media tanam berpengaruh sangat nyata terhadap pertambahan luas daun, hasil uji lanjut menunjukkan bahwa penggunaan jenis media tanam yang paling baik pada variabel tersebut adalah akar kadaka.

Hasil analisis ragam terhadap pertambahan luas daun kemudian diuji lanjut dengan uji DMRT taraf 5\% yang menunjukkan bahwa penggunaan akar kadaka sebagai media tanam anggrek Phalaenopsis pada pertumbuhan vegetatif fase aklimatisasi memberikan hasil yang paling baik. Penggunaan akar kadaka ternyata meningkatkan luas daun anggrek sebesar 3.61 $\mathrm{cm}^{2} \tan ^{-1}$ dibanding pakis dan dan sabut kelapa yang hanya $3.01 \mathrm{~cm}^{2} \tan ^{-1}$ dan $2.85 \mathrm{~cm}^{2} \tan ^{-1}$. Hal tersebut menunjukkan bahwa penggunaan pakis yang umumnya digunakan untuk media tumbuh tanaman anggrek dapat digantikan dengan akar kadaka. 
Tabel 1. Rekapitulasi hasil analisis ragam pertumbuhan aklimatisasi tanaman anggrek pada berbagai jenis media tanam dan konsentrasi pupuk daun.

\begin{tabular}{|c|c|c|c|c|}
\hline No & Variabel Pengamatan & $\begin{array}{l}\text { Media Tanam } \\
\text { (M) }\end{array}$ & $\begin{array}{l}\text { Konsentrasi } \\
\text { Pupuk Daun } \\
\text { (K) }\end{array}$ & $\begin{array}{c}\text { Interakasi Media Tanam x } \\
\text { Konsentrasi Pupuk Daun (M } \\
\text { X K) }\end{array}$ \\
\hline \multirow[t]{2}{*}{1} & Pertambahan Jumlah & & & \\
\hline & Daun & tn & tn & tn \\
\hline \multirow[t]{2}{*}{2} & Pertambahan Luas & & & \\
\hline & Daun & $* *$ & $* *$ & tn \\
\hline \multirow[t]{2}{*}{3} & Pertambahan & & & \\
\hline & Diameter Batang & tn & tn & tn \\
\hline \multirow[t]{2}{*}{4} & Pertambahan Jumlah & & & \\
\hline & Klorofil & tn & $* *$ & tn \\
\hline 5 & Jumlah Stomata & $\operatorname{tn}$ & tn & tn \\
\hline
\end{tabular}

Tabel 2. Nilai rerata hasil pengamatan variabel pertumbuhan tanaman anggrek pada perlakuan penggunaan jenis media tanam

\begin{tabular}{|c|c|c|c|c|c|}
\hline Perlakuan & $\begin{array}{l}\text { Pertambahan } \\
\text { Jumlah } \\
\text { Daun } \\
\left(\text { helai } \tan ^{-1}\right)\end{array}$ & $\begin{array}{c}\text { Pertambahan } \\
\text { Luas } \\
\text { Daun } \\
\left(\mathrm{cm}^{2} \tan ^{-1}\right)\end{array}$ & $\begin{array}{c}\text { Pertambahan } \\
\text { Diameter } \\
\text { Batang } \\
\left(\mathrm{cm} \mathrm{tan}^{-1}\right)\end{array}$ & $\begin{array}{c}\text { Pertambahan } \\
\text { Jumlah } \\
\text { Klorofil } \\
\text { (Unit) SPAD) }\end{array}$ & $\begin{array}{c}\text { Jumlah } \\
\text { Stomata } \\
\text { (unit) }\end{array}$ \\
\hline Pakis & 0.36 & $3.01 \mathrm{~b}$ & 2.38 & 1.47 & 1.68 \\
\hline Serabut kelapa & 0.31 & $2.85 \mathrm{~b}$ & 2.45 & 1.34 & 1.54 \\
\hline Akar kadaka & 0.25 & $3.61 \mathrm{a}$ & 2.62 & 1.55 & 1.60 \\
\hline
\end{tabular}

Keterangan: Angka-angka yang diikuti oleh huruf yang sama berbeda pada kolom yang sama adalah berbeda nyata pada uji DMRT taraf $\alpha$ 5\%.

Hal ini menjadi solusi alternatif mengingat pakis yang umum digunakan sebagai media tanam tanaman anggrek telah termasuk ke dalam CITES (Convention on International Trade in Endangered Species) yaitu daftar tanaman yang dilindungi di dunia karena telah hampir punah. Hasil ini sejalan dengan penelitian Tirta (2006), yang menyebutkan bahwa akar kadaka memiliki serat rapat dan halus sehingga dapat menyimpan air dan hara lebih baik dibandingkan dengan media lainnya (media yang digunakan meliputi pakis, akar kadaka, dan arang dari kayu kopi).

Hasil analisis menunjukkan bahwa perlakuan media tanam tidak memberikan hasil berbeda nyata terhadap variabel pertambahan jumlah daun (Tabel 1). Hal ini karena tanaman yang diteliti berada pada tahap aklimatisasi, yang mana tanaman butuh beradaptasi dengan lingkungan hidup yang baru salah satunya dengan menggugurkan daunnya untuk mengurangi jumlah kehilangan air pada tanaman, sehingga tanaman mampu bertahan hidup. Hal ini sejalan dengan penelitian Widiarsih dan Ita (2008), yang menjelaskan bahwa pada fase aklimatisasi, seluruh dosis perlakuan menunjukkan turunnya jumlah daun setelah dua minggu. Terdapat daun yang layu hampir pada seluruh tanaman. Peristiwa ini wajar ditemui selama masa aklimatisasi, karena tanaman harus beradaptasi dengan lingkungan yang cenderung lebih kering daripada kondisi kultur jaringan. Tanaman sering kali menggugurkan daun demi mengurangi penguapan, dalam proses mempertahankan kelangsungan hidupnya. Menurut Wulandari dan Sukma (2014), jumlah daun yang diamati setiap bulan setelah perlakuan aklimatisasi hasil persilangan menunjukkan hasil yang tidak berpengaruh nyata. Penambahan jumlah daun planlet anggrek selama tahap aklimatisasi bersifat fluktuatif karena adanya pergantian fase antara daun muda yang baru tumbuh dan daun dewasa yang mati selama berlangsungnya pengamatan.

Pertambahan luas daun menjadi peubah pertumbuhan untuk mengetahui pertumbuhan suatu tanaman. Berdasarkan Tabel 1 memperlihatkan bahwa Uji F memberikan hasil 
bahwa perlakuan media tanam memberikan pengaruh yang sangat nyata terhadap pertambahan luas daun. Kemudian hasil uji lanjut menunjukkan bahwa media tanam akar kadaka merupakan media yang paling baik untuk peubah tersebut (Tabel 2). Menurut Raynalta dan Sukma (2013), seluruh komposisi media (BAP, air kelapa, dan dan media MS) berpengaruh positif terhadap pertumbuhan daun dan akar planlet anggrek Phalaenopsis amabilis.

Akar kadaka mampu mengikat serta menyediakan air dan hara dengan baik, sehingga dapat mendukung proses fotosintesis tanaman. Kemampuan akar kadaka dalam menjaga kelembaban juga mampu menghindari tanaman dari penyakit busuk akar, hal tersebut dapat mendukung pertumbuhan tanaman menjadi optimal tanpa gangguan serangan penyakit. Karakteristik akar kadaka tersebut mampu mendukung proses fotosintesis melebihi media tanam pakis dan sabut kelapa, dikarenakan pada prosesnya memerlukan air dan unsur hara terutama nitrogen (untuk pertumbuhan vegetatif).

Kelebihan dari akar kadaka juga dapat menopang tanaman sehingga tumbuh tegak karena akar anggrek dapat melekat dengan baik pada akar kadaka, sesuai dengan pernyataan Dewi et al. (2014), bahwa tanaman yang berdiri tegak dapat memanfaatkan cahaya matahari dan udara lebih banyak. Cahaya matahari dan kandungan yang terdapat di udara dibutuhkan dalam proses metabolisme di dalam tanaman, khususnya fotosintesis yang dapat menghasilkan fotosintat. Air, unsur hara, cahaya, dan kandungan dalam udara merupakan komponen dalam fotosintesis, sehingga jika tanaman mendapatkan komponen tersebut yang didukung oleh media akar kadaka, maka hasil fotosintat menjadi lebih tinggi pula dibandingkan dengan penggunaan media tanam lainnya.

\section{Pengaruh Perlakuan Konsentrasi Pupuk Daun terhadap Variabel Pengamatan}

Perlakuan konsentrasi pupuk daun memberikan pengaruh yang sangat nyata terhadap pertambahan luas daun dan pertambahan jumlah klorofil, namun tidak memberikan pengaruh nyata terhadap pertambahan jumlah daun, pertambahan diameter batang, dan jumlah stomata (Tabel 1).

Pola pertambahan daun pada setiap tanaman anggrek Phalaenopsis yang diteliti mengalami kenaikan dan penurunan. Perlakuan konsentrasi pupuk daun tidak memberikan pengaruh nyata terhadap pertambahan jumlah daun. Hal tersebut karena tanaman anggrek menggugurkan daunnya agar hasil fotosintat tanaman digunakan untuk memperbesar luas daun. Selain itu juga dikarenakan anggrek menggugurkan daunnya untuk mengurangi penguapan pada proses aklimatisasi.

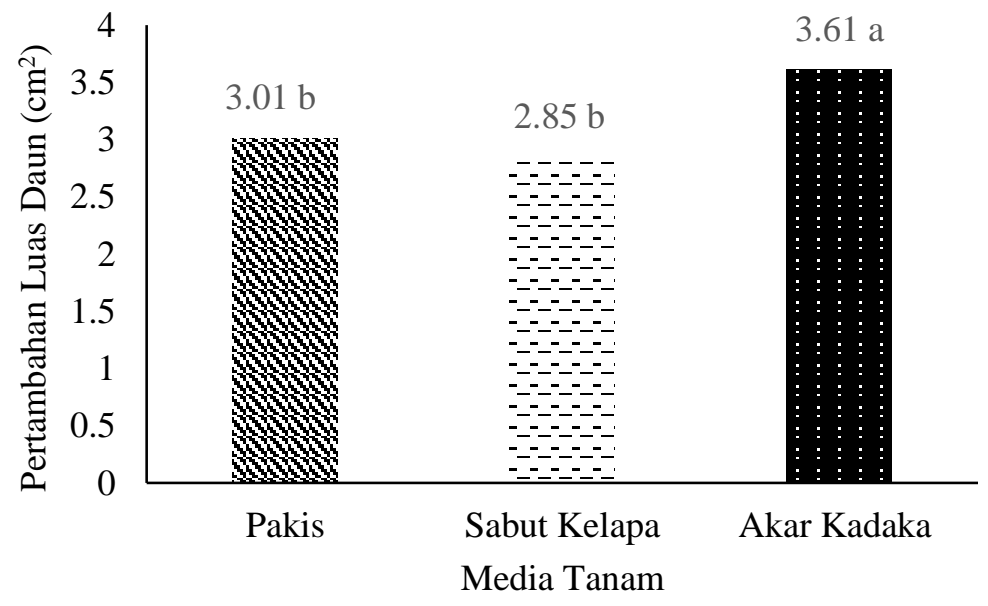

Gambar 1. Diagram batang rerata pertambahan luas daun anggrek Phalaenopsis pada media tanam pakis, sabut kelapa, dan akar kadaka 
Hasil analisis regresi (Gambar 2) menunjukkan bahwa perlakuan konsentrasi pupuk memberikan hasil yang nyata terhadap pertambahan jumlah klorofil dengan nilai determinasi sebesar 0.908 yang artinya perlakuan konsentrasi pupuk daun memberikan pengaruh sebesar $90.8 \%$ terhadap pertambahan jumlah klorofil dan persamaan $\mathrm{Y}=-0.095 \mathrm{x}^{2}+0.339 \mathrm{x}+1.274$. Konsentrasi pupuk yang paling baik untuk peubah tersebut adalah $2 \mathrm{~g} \mathrm{~L}^{-1}$, konsentrasi pupuk yang lebih tinggi memberikan hasil pengamatan yang lebih rendah karena setiap tanaman memiliki kapasitas masing-masing untuk menerima pasokan hara sehingga menghasilkan pertumbuhan yang optimal.

Nitrogen merupakan salah satu hara makro penyusun asam amino, klorofil dan senyawa lainnya dalam proses metabolisme. Kandungan klorofil yang tinggi dapat meningkatkan proses fotosintesis, sehingga fotosintat yang dihasilkan semakin tinggi. Terjadi peningkatan tinggi planlet dan luas daun, akibat fotosintat yang tinggi (Widiastoety dan Kartikaningrum, 2003). Menurut Pramitasari et al. (2016), nitrogen merupakan unsur penting dalam penyusunan klorofil. Klorofil merupakan komponen utama dalam proses fotosintesis. Nitrogen berfungsi sebagai pembentuk klorofil yang berperan penting dalam proses fotosintesis. Semakin tinggi pemberian nitrogen (sampai batas optimumnya), maka jumlah klorofil yang terbentuk akan meningkat. Meningkatnya jumlah klorofil akan menjadikan laju fotosintesis juga semakin meningkat, sehingga dapat mempercepat pertumbuhan vegetatif tanaman. Fotosintat yang dihasilkan digunakan untuk pertumbuhan organ-organ tanaman pada fase vegetatif.

Analisis regresi pada Gambar 3, menunjukkan bahwa persamaan regresi hubungan antara konsentrasi pupuk dan pertambahan luas daun tanaman anggrek Phalaenopsis adalah $\mathrm{Y}=-0.31 \mathrm{x}^{2}+1.536 \mathrm{x}$ +1.936 , dengan determinasi sebesar 0.688 yang menunjukkan bahwa perlakuan konsentrasi pupuk daun mempunyai pengaruh $68.8 \%$ terhadap pertambahan luas daun. Unsur nitrogen yang terkandung dalam pupuk yang digunakan membantu pembentukan klorofil pada tanaman. Oleh karena itu, hasil fotosintat yang digunakan untuk pertumbuhan tanaman juga semakin meningkat, salah satu peubahnya adalah luas daun.

Tabel 3. Nilai rerata hasil pengamatan variabel pertumbuhan tanaman anggrek pada perlakuan konsentrasi pupuk daun

\begin{tabular}{|c|c|c|c|c|c|}
\hline $\begin{array}{c}\text { Perlakuan } \\
\text { (Konsentrasi } \\
\text { Pupuk } \\
\text { Greener }\left(\mathrm{g} \mathrm{L}^{-1}\right)\end{array}$ & $\begin{array}{l}\text { Pertambahan } \\
\text { Jumlah } \\
\text { Daun } \\
\left(\text { helai } \tan ^{-1}\right)\end{array}$ & $\begin{array}{l}\text { Petambahan } \\
\text { Luas } \\
\text { Daun } \\
\left(\mathrm{cm}^{2} \tan ^{-1}\right)\end{array}$ & $\begin{array}{l}\text { Pertambahan } \\
\text { Diameter } \\
\text { Batang } \\
\left(\mathrm{cm} \mathrm{tan}^{-1}\right)\end{array}$ & $\begin{array}{c}\text { Pertambahan } \\
\text { Jumlah } \\
\text { Klorofil } \\
\text { (Unit SPAD) }\end{array}$ & $\begin{array}{c}\text { Jumlah } \\
\text { Stomata } \\
\text { (unit) }\end{array}$ \\
\hline 0 & 0.18 & $2.16 \mathrm{c}$ & 2.33 & $1.29 \mathrm{~b}$ & 1.68 \\
\hline 1 & 0.26 & $2.49 \mathrm{c}$ & 2.41 & $1.47 \mathrm{ab}$ & 1.59 \\
\hline 2 & 0.41 & $4.44 \mathrm{a}$ & 2.60 & $1.62 \mathrm{a}$ & 1.61 \\
\hline 3 & 0.37 & $3.53 \mathrm{~b}$ & 2.59 & $1.42 \mathrm{ab}$ & 1.56 \\
\hline
\end{tabular}

Keterangan: Angka-angka yang diikuti huruf yang berbeda pada variabel dan perlakuan yang sama menunjukkan berbeda nyata pada uji DMRT 5\%.

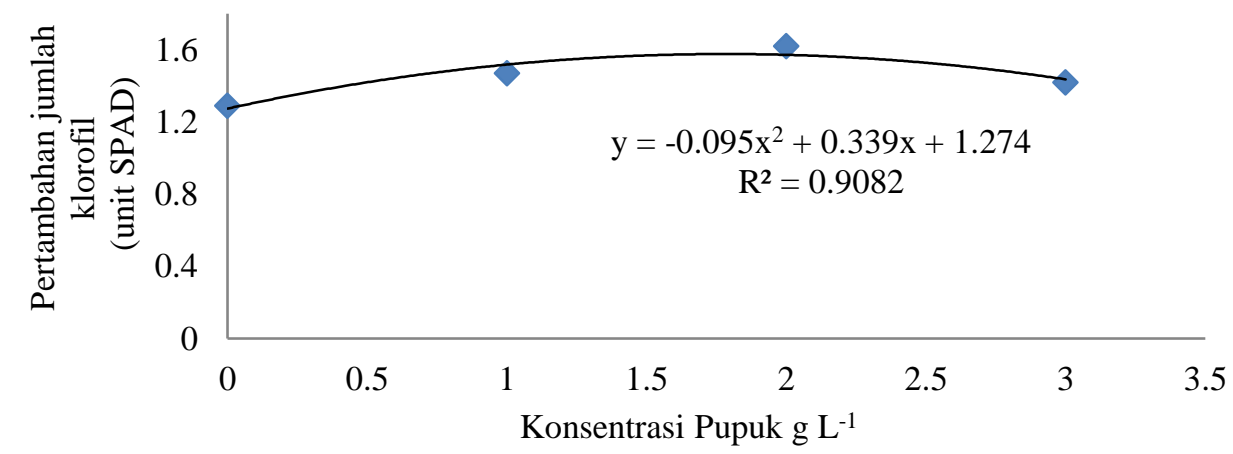

Gambar 2. Grafik hubungan antara konsentrasi pupuk dan pertambahan jumlah klorofil 


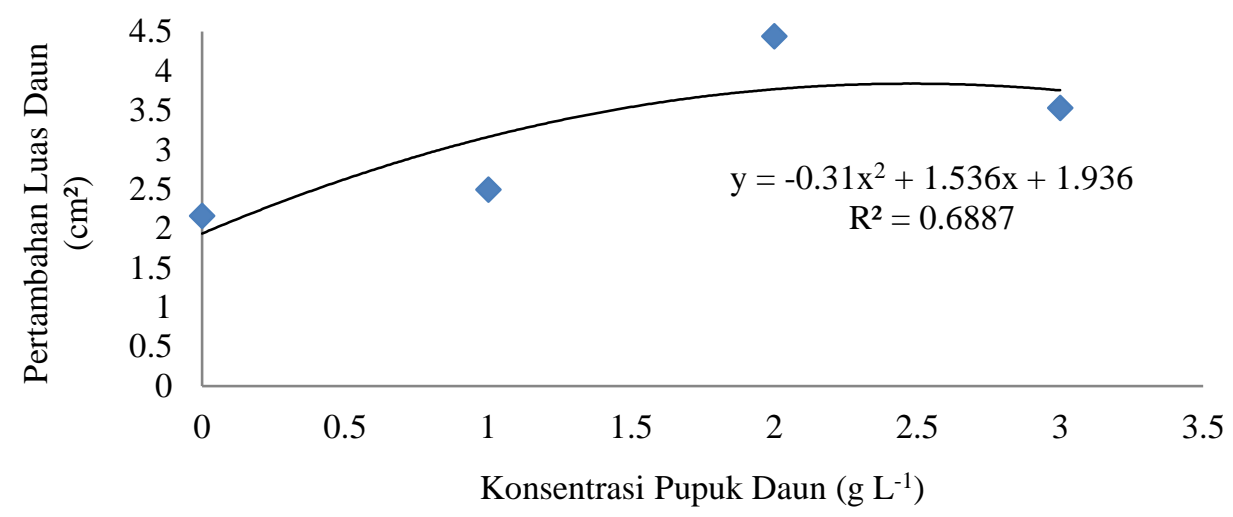

Gambar 3. Grafik hubungan antara konsentrasi pupuk dan pertambahan luas daun tanaman anggrek Phalaenopsis

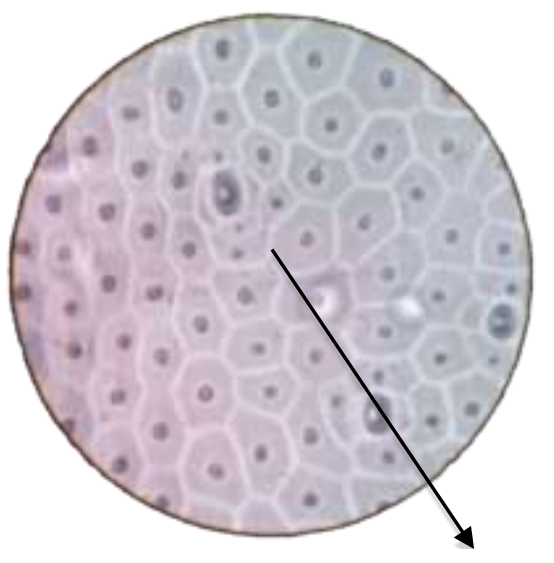

Stomata

Gambar 4. Stomata tanaman anggrek Phalaenopsis pada perbesaran 400x.

Tumbuhan mampu memproduksi makanannya sendiri dengan mekanisme yang disebut sebagai fotosintesis. Fotosintesis adalah proses penyimpanan energi yang berlangsung di dalam daun dan bagian hijau lainnya (Sudiana dan Elfa, 2008). Hal ini sejalan dengan hasil penelitian Gomies et al. (2012), yang menunjukkan bahwa peningkatan luas daun disebabkan karena pupuk organik cair yang dapat langsung menyediakan nitrogen yang dibutuhkan tanaman untuk pertumbuhannya.

Stomata berperan sebagai alat untuk penguapan dan tempat pertukaran karbon dioksida dalam proses fisiologi yang berhubungan dengan produksi. Stomata berperan penting sebagai alat untuk adaptasi tanaman terhadap cekaman kekeringan, pada kondisi cekaman kekeringan maka stomata akan menutup sebagai upaya untuk menahan laju transpirasi (Lestari, 2006). Bentuk stomata tanaman anggrek Phalaenopsis yang dilihat di bawah mikroskop adalah berbentuk ginjal dan letaknya tidak teratur (Gambar 4). Hal ini sesuai dengan Rompas et al. (2011), yang menyebutkan stomata daun anggrek Phalaenopsis amabilis berbentuk ginjal. Hasil analisis ragam menunjukkan bahwa perlakuan konsentrasi pupuk daun yang berbeda tidak memberikan hasil yang nyata terhadap jumlah stomata. Jumlah stomata dihitung menggunakan mikroskop dengan perbesaran 400 kali dengan luas pandang $0.14 \mathrm{~mm}^{2}$. Hasil analisis yang menunjukkan tidak ada pengaruh nyata antara perlakuan yang diberikan dengan jumlah stomata karena umur tanaman anggrek yang diujikan berumur 11 minggu, sehingga perlakuan pupuk belum memberikan perbedaan yang signifikan terhadap hasil jumlah stomata tanaman anggrek Phalaenopsis. Menurut Tirta (2006), kebutuhan tanaman anggrek akan unsur hara sama dengan tumbuhan lainnya, hanya anggrek membutuhkan waktu yang cukup lama untuk memperlihatkan gejala-gejala defisiensi, mengingat pertumbuhan anggrek sangat lambat.

Jumlah stomata terlihat tidak berbeda (Tabel 2) seperti pada penelitan Sukma dan Setiawati (2010), bahwa pemberian pupuk daun pada anggrek Dendrobium menunjukkan persentase stomata yang membuka pagi hari (49\%), siang (48.19\%), dan sore (46.34\%) tidak menunjukkan perbedaan yang signifikan. Jika nutrisi diberikan pada saat stomata banyak yang membuka, diduga nutrisi yang dapat diserap tanaman lebih banyak sehingga dapat meningkatkan pertumbuhan dan perkembangan tanaman. 


\section{Interaksi Kombinasi Perlakuan Jenis Media Tanam dan Konsentrasi Pupuk Daun terhadap Variabel Pertumbuhan}

Analisis ragam (uji F) data variabel pengamatan memberikan hasil yang menunjukkan bahwa interaksi kombinasi perlakuan jenis media tanam dan konsentrasi pupuk daun yang berbeda tidak memberikan pengaruh nyata terhadap pertambahan jumlah daun, pertambahan luas daun, pertambahan diameter batang, pertambahan jumlah klorofil, dan jumlah stomata (Tabel 1). Hal ini karena perlakuan media tanam dan pemberian konsentrasi pupuk yang diuji tidak saling ketergantungan dalam pemanfaatannya pada tanaman anggrek Phalaenopsis. Menurut Suwandi (2009), tidak adanya interaksi antara perlakuan yang diberikan disebabkan oleh pengaruh dari masing-masing faktor perlakuan secara mandiri lebih berpengaruh daripada faktor interaksinya.

\section{KESIMPULAN}

Akar kadaka dapat menggantikan peran pakis dan sabut kelapa sebagai media aklimatisasi anggrek Phalaenopsis. Hal tersebut karena akar kadaka meningkatkan pertambahan luas daun dibanding pakis dan sabut kelapa masing-masing sebesar $22.64 \%$ dan $57.69 \%$. Akar kadaka juga meningkatkan pertambahan diameter batang dibanding pakis dan sabut kelapa masing masing sebesar $12.41 \%$ dan $35.29 \%$. Konsentrasi pupuk daun 2 $\mathrm{g} \mathrm{L}^{-1}$ merupakan konsentrasi paling baik yang dapat meningkatkan pertambahan luas daun sebesar $67.45 \%$ dan pertambahan jumlah klorofil sebesar $27.76 \%$ dibandingkan tanaman yang tidak diberi perlakuan pupuk. Kombinasi jenis media tanam dan konsentrasi pupuk tidak menunjukkan pengaruh interaksi terhadap pertumbuhan tanaman anggrek Phalaenopsis pada fase aklimatisasi

\section{UCAPAN TERIMA KASIH}

Penulis menyampaikan ucapan terima kasih kepada Universitas Jenderal Soedirman melalui Lembaga Penelitian dan Pengabdian Universitas Jenderal Soedirman yang telah memberikan dana penelitian skim Peningkatan
Kompetensi melalui Surat Keputusan Ketua LPPM Nomor: Kept.235/UN23.14/PN.01.00/ 2018.

\section{DAFTAR PUSTAKA}

Ari, A.N.H.G., M. Melati, S.A. Aziz. 2016. Produksi bibit tempuyung (Sonchus arvensis L.) dengan komposisi dan volume media tumbuh yang berbeda. J. Hort. Indonesia. 7(3): 195-203.

Dewi, T.A., Yafisham, Nuraini. 2014. Respon pertumbuhan anggrek Dendrobium terhadap jenis media tanam dan pupuk daun. J. Penelitian Pertanian Terapan. 14(1): 76-82.

Gomies, L., H. Rehatta, J. Nandissa. 2012. Pengaruh pupuk organik cair RI1 terhadap pertumbuhan dan produksi tanaman kubis bunga (Brassica oleracea var. botrytis L.). Agrologia. 1(1):13-20.

Kartana, S.N. 2017. Uji berbagai media tanam dalam meningkatkan pertumbuhan bibit anggrek bulan yang berasal dari alam. Jurnal Penelitian PIPER. 24(13): 19-25.

Latif, S.M. 1960. Bunga Anggrek Permata Belantara. Sumur. Bandung.

Lestari, E.G. 2006. Hubungan antara kerapatan stomata dengan ketahanan kekeringan pada somaklon padi Gajahmungkur, Towuti, dan IR 64. Biodiversitas. 7(1): 44-48

Raynalta, E., D. Sukma. 2013. Pengaruh komposisi media dalam perbanyakan Protocorm Like Bodies, pertumbuhan planlet, dan aklimatisasi Phalaenopsis amabilis. J. Hort. Indonesia. 4(3):131-139.

Pramitasari, H.E., T. Wardiati, M. Nawawi. 2016. Pengaruh dosis pupuk nitrogen dan tingkat kepadatan tanaman terhadap pertumbuhan dan hasil tanaman kailan (Brassica oleraceae L.). Jurnal Produksi Tanaman. 4(1): 49-56. 
Rompas, Y., L.R. Henny, J.R. Marhaenus. 2011. Struktur sel epidermis dan stomata daun beberapa tumbuhan suku Orchidaceae. Jurnal Bioslogos. 1(1): 1-7.

Sudiana, D., D. Elfa. 2008. Analisis Indeks Vegetasi menggunakan Data Satelit NOAA/AVHRR dan TERRA/AQUAMODIS. Seminar on Intelligent Technology and Its Applications ISBN 978-979-8897-24-5. Departemen Teknik Elektro, Universitas Indonesia. Depok.

Sukma, D., A. Setiawati. 2010. Pengaruh waktu dan frekuensi aplikasi pupuk daun terhadap pertumbuhan dan pembungaan anggrek Dendrobium 'Tong Chai Gold'. J. Hort. Indonesia. 1(2): 96-103.

Sutedjo, M.M. 1999. Pupuk dan Cara Pemupukan. Rineka Cipta. Jakarta.

Suwandi. 2009. Menakar kebutuhan hara tanaman dalam pengembangan inovasi budidaya sayuran berkelanjutan. Pengembangan Inovasi Pertanian. 2(2): 131-147.
Tirta, I.G. 2006. Pengaruh beberapa jenis media tanam dan pupuk daun terhadap pertumbuhan vegetatif anggrek Jamrud (Dendrobium macrophyllum A. Rich). Biodeversitas. 7(1): 81-84.

Widiarsih, S., D. Ita. 2008. Pengaruh Dosis Iradiasi Sinar Gamma Terhadap Laju Pertumbuhan ANggrek Bulan (Phalaenopsis amabilis (L.) BI.) pada Fase Aklimatisasi dan Vegetatif Awal. Prosiding Simposium dan Pameran Teknologi Isotop dan Radiasi. BATAN. Jakarta.

Widiastoety, D., S. Kartikaningrum. 2003. Pemanfaatan ekstrak ragi dalam kultur In Vitro planlet media anggrek. J. Hort. 13(2):82-86.

Wulandari, T., D. Sukma. 2014. Karakterisasi morfologi dan pertumbuhan populasi planlet anggrek Phalaenopsis hasil persilangan selama tahap aklimatisasi. J. Hort. Indonesia. 5(3):137-147. 